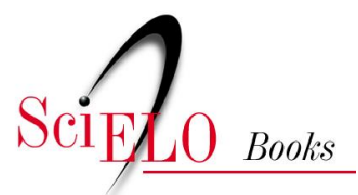

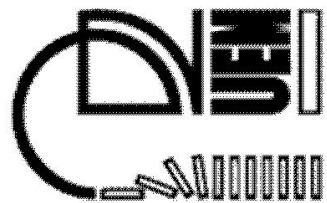

\title{
7 A cafeicultura no Paraná
}

\author{
Angelo Priori \\ Luciana Regina Pomari \\ Silvia Maria Amâncio \\ Veronica Karina Ipólito
}

PRIORI, A., et al. História do Paraná: séculos XIX e XX [online]. Maringá: Eduem, 2012. A cafeicultura no Paraná. pp. 91-104. ISBN 978-85-7628-587-8. Available from SciELO Books $<\underline{\text { http://books.scielo.org }>\text {. }}$

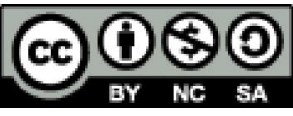

All the contents of this chapter, except where otherwise noted, is licensed under a Creative Commons Attribution-Non Commercial-ShareAlike 3.0 Unported.

Todo o conteúdo deste capítulo, exceto quando houver ressalva, é publicado sob a licença Creative Commons Atribuição Uso Não Comercial - Partilha nos Mesmos Termos 3.0 Não adaptada.

Todo el contenido de este capítulo, excepto donde se indique lo contrario, está bajo licencia de la licencia Creative Commons Reconocimento-NoComercial-CompartirIgual 3.0 Unported. 


\section{7}

\section{A cafeicultura no Paraná}

O leitor, com certeza, já ouviu falar da pujança da cafeicultura paranaense entre os anos 1940 e 1970. E com certeza sabe o que significa as expressões 'ouro negro' e 'ouro verde'. Muito mais do que viver uma fase de produção, o café se transformou em orgulho paranaense por simbolizar riqueza, desenvolver cidades, atrair investidores e modernizar algumas regiões do Estado. Mas, afinal, se a cafeicultura paranaense teve grande destaque, por que nos dias atuais os grãos de café não ocupam o primeiro lugar na produção agrícola? É importante deixar claro que o Paraná assistiu ao auge e ao declínio da cafeicultura ao longo do século $\mathrm{XX}$. Mas, como tudo isso começou? De que forma o café chegou às terras paranaenses? Antes de esclarecermos essas e outras questões, que tal fazermos uma viagem pela história do café e sua propagação no continente americano e em solo brasileiro?

Com sua origem creditada ao continente africano, precisamente na região da Etiópia Central, o café teria se expandido para o Oriente por meio de comerciantes árabes. A expansão do café em terras europeias e americanas teria ocorrido com a intensificação das grandes navegações. As primeiras mudas de café teriam sido cultivadas na América no século XVIII e provavelmente seriam oriundas do território ultramarino francês de Reunion ${ }^{8}$, conhecido na época como Ilha de Bourbon. Inicialmente

8 Trata-se de uma ilha no Oceano Índico que ainda hoje é um departamento ultramarino da França. 
cultivada na Ilha Martinica, na região caribenha, durante os anos de 1720, a plantação de café adaptou-se ao clima dos trópicos. Em 1720 e 1780 já há notícias da existência do café em outras regiões caribenhas (como a Jamaica) e inclusive no próprio continente (como no México e na Venezuela). Também nesse período houve a introdução de mudas cafeeiras pelos holandeses em sua colônia americana, o Suriname.

Acredita-se que, no Brasil, o café foi introduzido em 1727 pelo militar Francisco de Mello Palheta quando foi enviado para intervir na questão de fronteira entre as Guianas Francesa e Holandesa. Palheta trouxe as primeiras sementes e a plantação cafeeira expandiu-se no Norte e Nordeste brasileiro, chegando ao Rio de Janeiro em 1760 e estendendose para a região de Minas Gerais após a crise dos veios auríferos (POZZOBON, 2006). Nessa época, o café já se encontrava no mercado e com grande valor comercial, pois na Europa e nos Estados Unidos o consumo da bebida estava crescendo cada vez mais.

No início, a cultura do café não teve muito apelo dos agricultores brasileiros, que naquele período estavam interessados no cultivo da canade-açúcar, produto agrícola de maior renda na economia. Mas, em curto espaço de tempo o café já substituía a cultura canavieira, pois a demanda mundial daquele era bem maior e também exigia menor mão de obra. Além disso, diferentemente da cana-de-açúcar, os pés de café reproduziam-se de 30 a 40 anos. Assim, entre 1820 a 1870, o café ocupou, aos poucos, a plantação canavieira e atingiu o auge de sua produção. Tinha início então uma nova etapa econômica do país.

O cultivo do café expandiu-se pelas terras brasileiras e, pelas condições climáticas, se alastrou rapidamente pelo vale do rio Paraíba, chegando a São Paulo na década de 1880. Caio Prado Júnior (1981) considera que o século XIX foi marcado por uma revolução no que se refere à distribuição de suas áreas produtivas. Na visão do autor, dois fatos básicos sustentam mudanças bruscas na área agrícola: o primeiro seria o deslocamento dos centros econômicos das velhas regiões cultiváveis do Norte para as mais recentes do Centro-sul (principalmente o Rio de 
Janeiro, algumas áreas fronteiriças de Minas Gerais e São Paulo). O outro fator seria a decadência das lavouras tradicionais do Brasil (como a canade-açúcar, algodão e o tabaco) e o desenvolvimento do café, que até então não possuía muita importância no cenário econômico brasileiro, mas que ao longo do século XIX aparece com destaque no campo das exportações brasileiras.

Em consonância com Roberto Simonsen (1977), nos anos que compreendem o período entre 1816 e 1822 foi exportada uma média anual de 2 milhões de arrobas (equivalente a 30.000 t) de café pelo porto do Rio de Janeiro. Na análise de Caio Prado Júnior (1981), entre 1821 e 1830, foi registrada uma queda na venda de café, contando com a embarcação de 19.068 toneladas. No entanto, esse autor reconhece que, a partir da década de 1840, o café alavancou o mercado e se tornou o principal produto brasileiro de exportação. De 1856 a 1860 o café respondia por 49\% das exportações brasileiras. Já nos anos de 1910 representava 65\%, atingindo o índice mais alto em 1920 com o percentual de 70\% das exportações.

\section{O café no Paraná}

No fim do século XIX e no início do século XX a extensão dos cafeeiros paulistas atingiu o Paraná. Com o aumento excessivo da produção e da oferta, em 1902 o Estado de São Paulo adotou políticas de restrição da produção do café, proibindo o seu plantio por um período de cinco anos. Em função desse problema os fazendeiros paulistas optaram em procurar terras no Norte do Paraná, impulsionando a expansão cafeeira no Estado. Para Nadir Cancian (1981), a cafeicultura no Paraná representou a continuação da 'marcha para o oeste' dos paulistas, porque sempre visou a perspectivas de bons lucros. Os fazendeiros paulistas adentraram no Paraná quando as terras daqueles estavam se tornando escassas e com baixa fertilidade. Com isso buscavam novas terras para aumentar a produção e consequentemente gerar maior rentabilidade por meio do desenvolvimento da agricultura comercial, com base na produção de café. 
No início do século XX, as terras roxas do Paranájá eram conhecidas por sua alta rentabilidade na produção cafeeira. A disponibilidade dessas terras, os incentivos públicos e a possibilidade de pagamento em condições facilitadas proporcionaram que muitos colonos e lavradores começassem a comprar terras no Norte do Paraná, instalando nessa área a produção cafeeira segundo o modelo paulista. Nesse sentido, a cafeicultura paranaense esteve muito ligada ao Estado de São Paulo e podemos dizer que ela era uma continuidade da economia paulista.

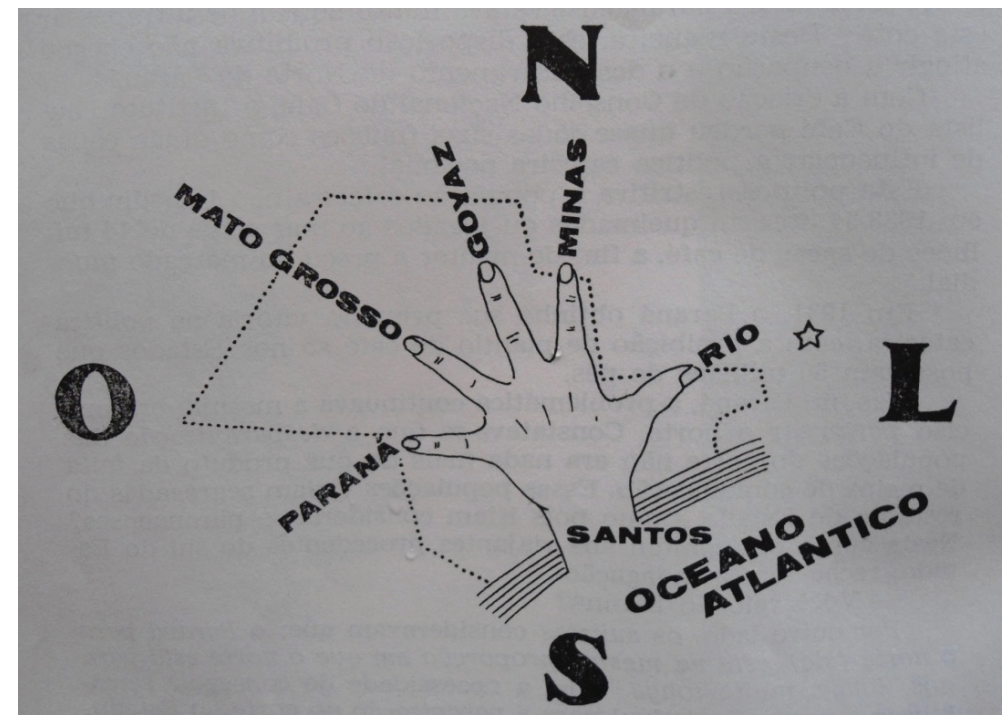

Figura 1: Hegemonia Paulista9 Fonte: Wachowicz (1987, p. 126).

A expansão do café no Paraná foi possível graças a uma série de questões, como aponta Nadir Cancian (1981): política econômica governamental, facilidade de aquisição de terras, clima propício, terras férteis e escoamento da produção por meio de ferrovias que ligavam o

9 Segundo Ruy Wachowicz (1987), a mão canhota aberta indicava a influência de São Paulo em relação aos Estados vizinhos. O Pulso indicava o Estado de São Paulo e o Porto de Santos, símbolo das exportações brasileiras até meados dos anos 1950. Os dedos indicavam os Estados próximos, como numa relação de dependência com o Estado de São Paulo. 
Estado ao Porto de Santos. Além disso, a autora enfatiza dois momentos (entre os anos de 1906 a 1929 e 1945 a 1960) de utilização máxima da terra em prol da produção cafeeira em uma conjuntura de preços favoráveis que estimulou novas formas de exploração da terra em nome do abastecimento do mercado e, como consequência, da inclusão do Paraná no cenário da economia nacional. No entanto, o declínio da produção cafeeira paranaense, a partir dos anos de 1960, resultou num esforço de diversificação agrícola e da modificação do nível de produção em algumas regiões do Estado. "Preços baixos corresponderiam à utilização da terra de modo diversificado. Preços altos, ao contrário, incentivariam a tendência para a monocultura" (CANCIAN, 1981, p. 15).

Em fins do século XIX e início do século XX a cultura cafeeira se expandiu por boa parte do setentrião paranaense, principalmente no Norte Velho. Portanto, podemos dizer que foi entre 1886 e 1906 que o café iniciou sua marcha rumo ao Paraná. A expansão cafeeira no Estado contou com fatores que iam além das fronteiras paranaenses: o encontro dos paulistas com a terra roxa, a organização da força de trabalho após a abolição do tráfico de escravos, o crescimento da imigração estrangeira, o amparo à produção, a melhoria dos meios de transporte, o incentivo aos financiamentos de máquinas, o surgimento de programas em defesa do café e a liberação do governo estadual de incentivar o plantio para estimular a progressiva expansão dos cafezais.

Nos anos 1920 e 1930, a expansão cafeeira atingiu a região denominada de Norte Novo (longo território do Norte do Paraná, localizado à margem esquerda do rio Tibagi. Nessa região, a colonização das terras e divisão dos lotes contou com ampla participação da Companhia de Terras Norte do Paraná. A princípio, esta empresa de origem britânica tinha por finalidades ocupar a região e estimular a produção de algodão para que esta matéria-prima se tornasse predominante na Inglaterra. Porém, isso não ocorreu, já que as primeiras plantações de algodão na região não obtiveram resultados satisfatórios. A empresa mudou o seu foco e começou a revender as suas terras em pequenas parcelas territoriais. Além dessa companhia, uma dezena de outras companhias de terras se 
instalou ao longo do Norte do Paraná, atuando na colonização e fixação de famílias em pequenas propriedades. Essa política atraiu para a região milhares de imigrantes, que vinham com o sonho de conquistar o seu pedaço de terra e produzir café e outros produtos alimentícios. O imigrante passou a ser considerado o fator de estabilidade para o desenvolvimento das cidades e o aumento da produção. Nessa época, o Paraná tornou-se a principal fronteira agrária e agrícola do país, atraindo tanto imigrantes europeus quanto migrantes nacionais.

\section{$O$ café no Paraná durante a primeira metade do século XX}

Como enfatizado acima, em fins do século XIX e início do século XX, o café já atingia o Paraná. No entanto, a oferta de café brasileiro no mercado internacional estava ameaçada em função do aumento da produção. Como resultado, surgiu a primeira medida restritiva em 1902. Tal iniciativa proibia o Estado de São Paulo de plantar cafeeiros por cinco anos. Por outro lado, e contraditoriamente, o governo paranaense incentivava a cafeicultura no estado, reduzindo as taxas de exportação do café e procurando incentivar o plantio e atrair novos fazendeiros. Outra medida política que teve reflexo na expansão do café no Paraná foi o chamado Convênio de Taubaté.

O Convênio de Taubaté foi um acordo firmado em 1906 entre os três Estados maiores produtores de café - São Paulo, Rio de Janeiro e Minas Gerais - que se comprometeram em restaurar o equilíbrio entre oferta e demanda, adquirindo, por meio de compra, os excedentes da produção cafeeira, a fim de conservar a renda dos produtores. Para custear essa medida, foi necessário implantar um novo imposto e fazer um empréstimo de 15 milhões de libras esterlinas. Além do mais, os Estados envolvidos no acordo se comprometeram a não plantar café pelo período de cinco anos. Como consequência, tais restrições beneficiaram os países concorrentes, os quais tiveram condições de aumentar a área do cultivo cafeeiro. Outro 
efeito do Convênio de Taubaté foi o impulso à industrialização de São Paulo, como medida alternativa à economia cafeeira (POZZOBON, 2006).

O Paraná nesse momento ainda não se apresentava como um dos principais produtores de café no Brasil. Por isso, não participou das medidas determinadas pelo Convênio de Taubaté. Aliás, esse acordo surtiu efeito contrário na economia paranaense: em vez de restringir a produção, o Paraná estimulou novos plantios. Diante dessa situação, vários cafeicultores compraram terras no Estado.

Mesmo assim, no período que compreende os anos de 1913 a 1917 foi registrada queda nos preços, principalmente em função de fatores externos que prejudicaram a dinâmica do mercado interno, como a Primeira Guerra Mundial e sua consequência direta com a falência de bancos, sobretudo os menores. Outra tentativa de elevação dos preços foi realizada entre os anos de 1917 a 1920, com intermediação do governo federal. Essa intervenção justificou-se com o fim da Primeira Guerra Mundial e na possibilidade de retomada do aumento das exportações. No entanto, em 1918 foi registrada uma grande geada e, como consequência, os preços duplicaram.

Com os preços do café em alta no mercado mundial e a crescente demanda, o Estado de São Paulo revogou a medida que proibia a plantação de novos cafezais. Mas a partir desse momento, São Paulo já tinha novos concorrentes. Em âmbito externo, outros países já estavam produzindo café, como Colômbia e Venezuela. E em âmbito interno, a expansão cafeeira marchava sem tréguas pelo Estado do Paraná.

Em 1920, o Paraná contabilizava 1.215 propriedades cafeeiras, tornando-se o sétimo maior Estado cultivador de café no país. Foi a partir dessa década, com a atuação da Companhia de Terras do Norte do Paraná (CNTP), que cada vez mais pessoas chegaram à região, impulsionando o povoamento e o estímulo à cafeicultura. Para Nadir Cancian, a ampliação da área cafeeira no Paraná "evidencia que os programas de defesa dos preços levaram à extensão do plantio que, conjugada a outros fatores, 
constituiu-se em poderoso estímulo à produção cafeeira no Paraná” (1981, p. 25).

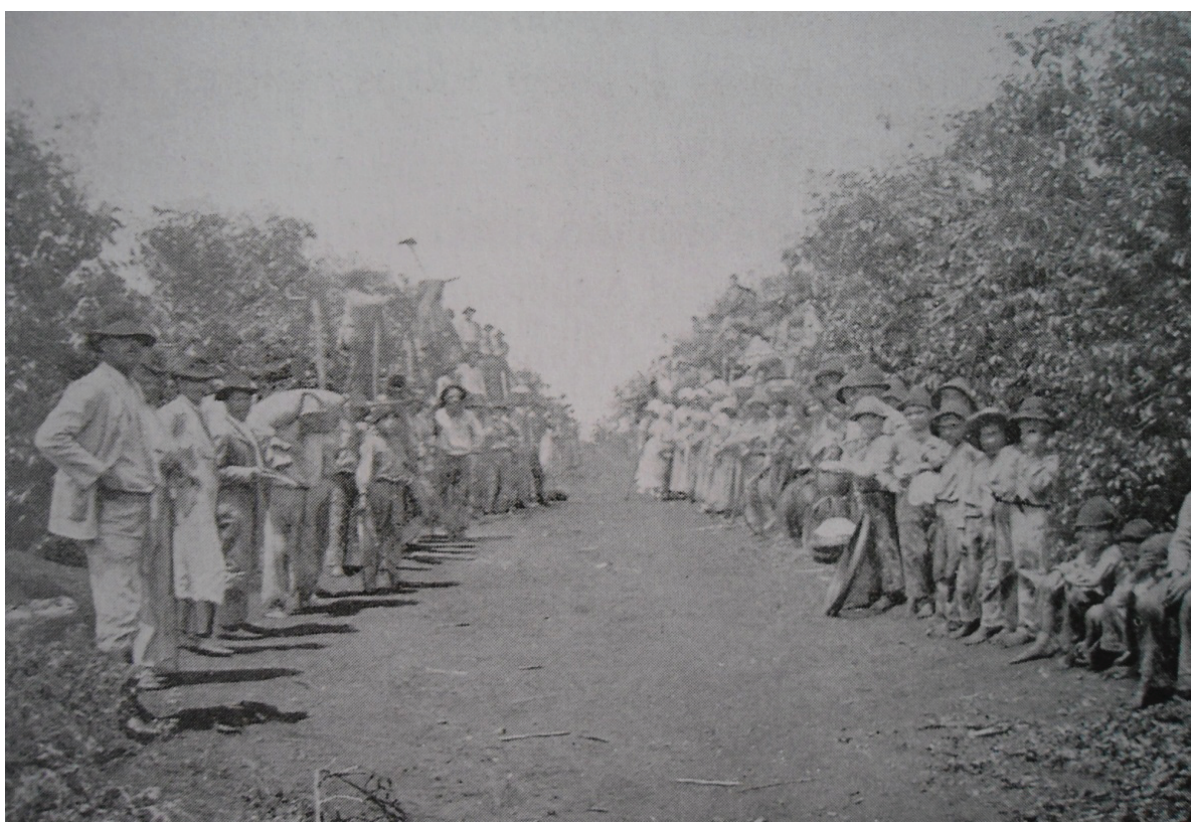

Figura 2: Famílias de colonos na lavoura (1920)

Fonte: Pozzobon (2006, p. 45).

A produção de café mudou a agricultura paranaense e se tornou uma riqueza estadual, com proteção e apoio do governo, trazendo desenvolvimento e crescimento para o Estado. O café tornou-se a cultura mais valorizada na época, devastou matas e trouxe fazendeiros de outros lugares que apareciam à procura de novas terras. Também abrigou um número bem grande de imigrantes estrangeiros e migrantes nacionais, que vinham para o Estado à procura de melhores condições de vida.

Diante desse quadro, algumas medidas foram tomadas, principalmente pelos maiores Estados produtores: incineração de café, proibição de novos plantios, instituição de taxas de exportação, havendo uma clara intervenção do Estado na economia. 


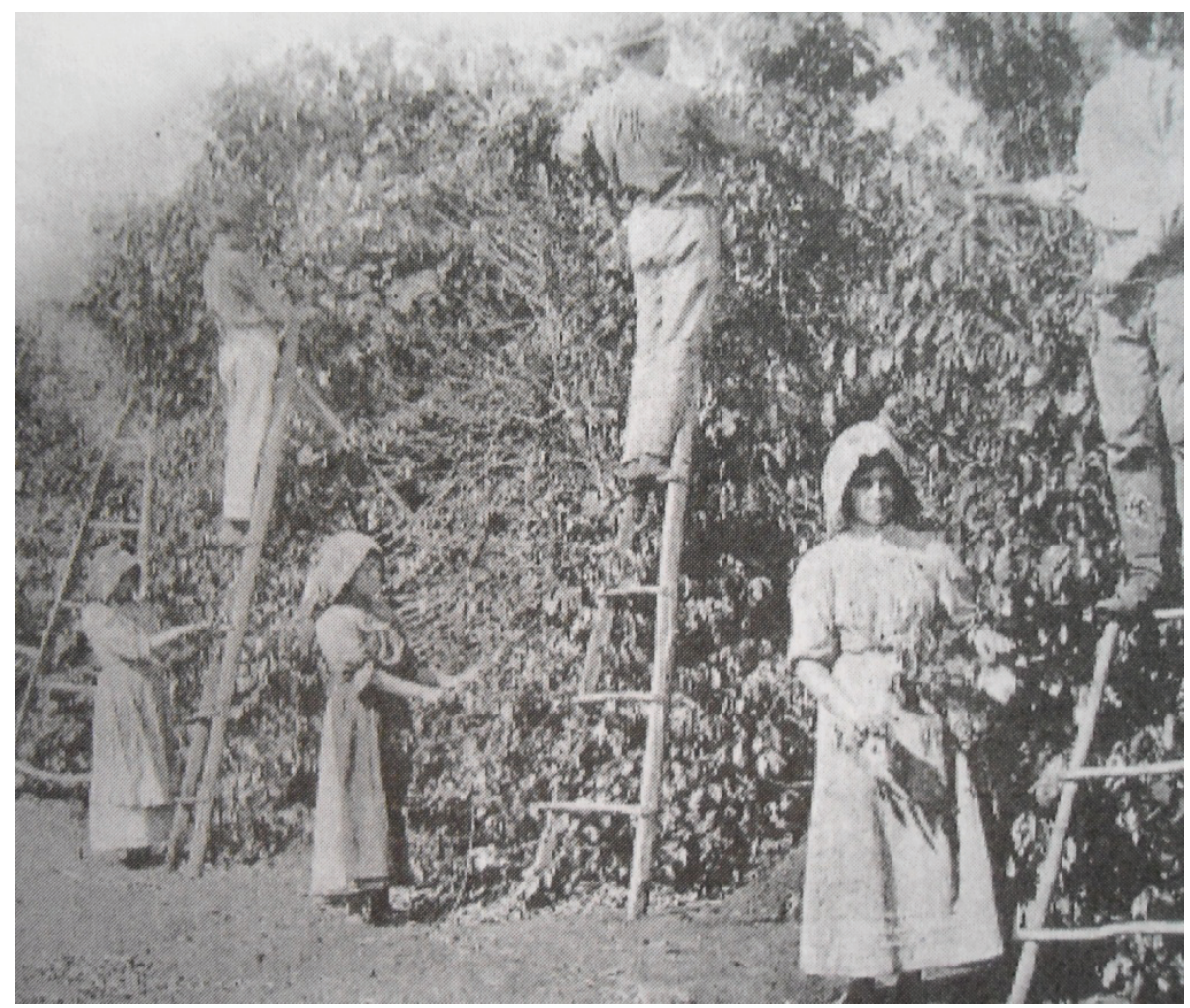

Figura 3. Derriça do café (1920)

Fonte: Pozzobon (2006, p. 45).

A grande depressão desestimulou a produção. No entanto, o Paraná não adotou as mesmas medidas restritivas dos outros Estados brasileiros produtores de café. É evidente que a crise atingiu fortemente a cafeicultura paranaense, sobretudo na região do Norte pioneiro, já que o plantio era exercido por grandes proprietários e que demandavam linhas de créditos e farta mão de obra para a produção. Mas isso não foi o suficiente para o Estado estancar a expansão do plantio. Pelo contrário. Com a ausência de lucros, que criava muitas dificuldades para as grandes propriedades, os cafeicultores paranaenses foram estimulados a desenvolverem a pequena e a média propriedade. Com a diminuição do tamanho das propriedades, os custos de manutenção foram reduzidos, pois o lavrador e sua família se tornaram a mão de obra principal. Essa mudança alterou o custo de 
produção já que esses pequenos e médios proprietários não precisavam mais gastar com trabalhadores assalariados. Em contrapartida, São Paulo limitava sua produção e lavradores paulistas se dirigiam com maior frequência para o Paraná, onde se estabeleciam em pequenas ou médias propriedades, motivados pela compra da terra, facilitada pelas empresas colonizadoras.

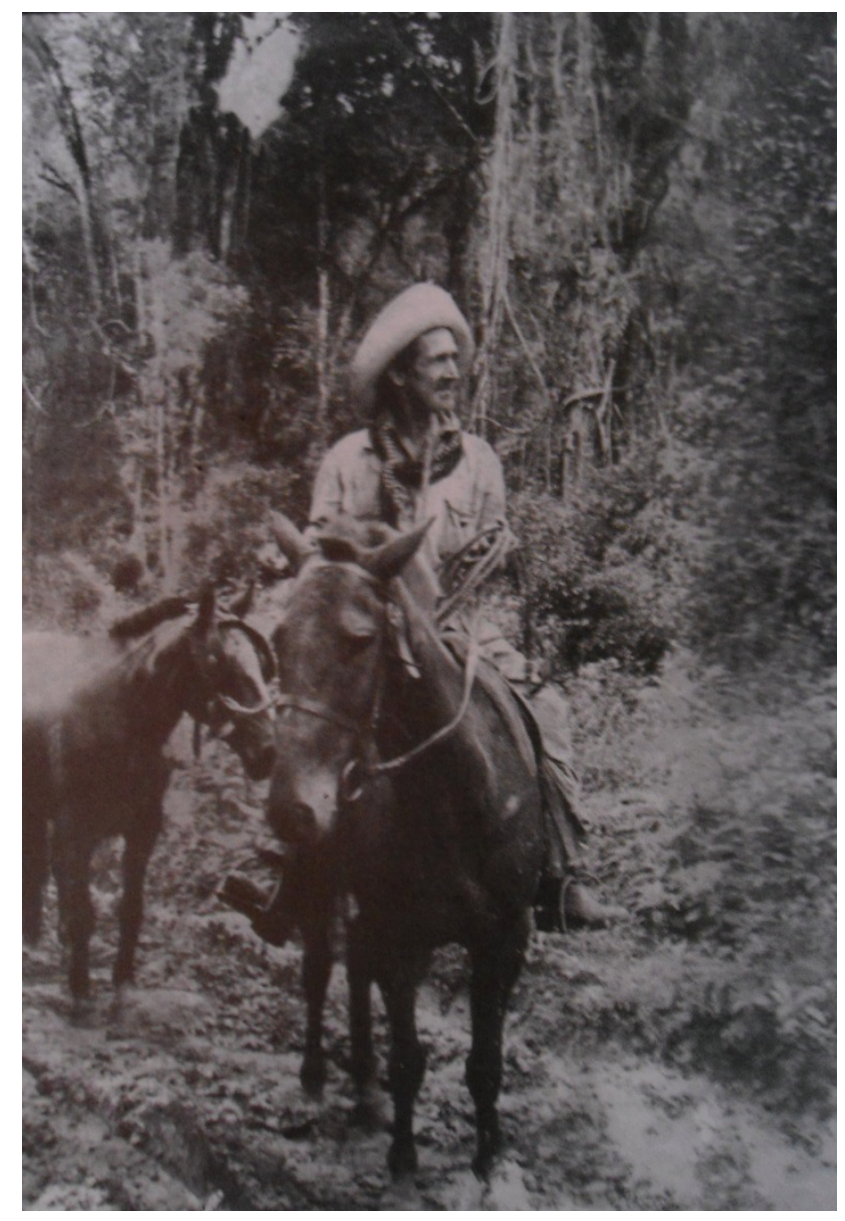

Figura 4: Rolândia, Paraná (1936) - 'Mateiro'

Fonte: Pozzobon (2006, p. 70). 


\section{O café no Paraná durante a segunda metade do século XX}

Finda a Segunda Guerra Mundial e o mundo voltando ao seu curso normal, a economia foi se estabilizando, e, com ela, a demanda por café. O início da segunda metade do século XX presenciou a estabilidade do mercado cafeeiro, com isso, novos plantios foram incentivados e a retomada da produção foi alavancada. Uma medida importante para a retomada da produção foi a definição de preços mínimos para a venda do café. Com isso, o produtor tinha a garantia da venda do seu produto por um preço mínimo estabelecido pelo Estado.

Com esses incentivos foram plantados novos cafezais, aumentando-se a procura por terras ainda virgens e com boa fertilidade. As perspectivas de lucro e as altas dos preços, aliadas ao surgimento de novas técnicas de plantio, secagem e armazenamento, aumentaram a rentabilidade do produto. Na década de 1950 a expansão do café já atingia o Noroeste paranaense. E é possível afirmar que talvez tenha sido a melhor década para os lucros dos produtores, mesmo com as intempéries climáticas constantes, como o caso da grande geada de 1955.

Analisando a distribuição dos cafeeiros, podemos notar que o impulso nas plantações do Paraná ocorreu entre 1949 e 1953, quando a média anual era em torno de 135 milhões de pés. Nesse período, com a manutenção nas altas dos preços do café, houve tendência à monocultura em alguns municípios, principalmente no Norte do Paraná, onde havia grandes extensões de cafezais.

A historiadora Nadir Cancian (1981) afirmava que a cafeicultura paranaense ocorreu em três fases: a primeira no Norte Velho, a partir do século XIX e início do século XX, terminando com a crise de 1929; a segunda no Norte Novo a partir de 1930 até o final da Segunda Guerra Mundial; e, por fim, a terceira teria ocorrido entre as décadas de 1940 a 1960, quando se encerrou a expansão da cafeicultura paranaense. 


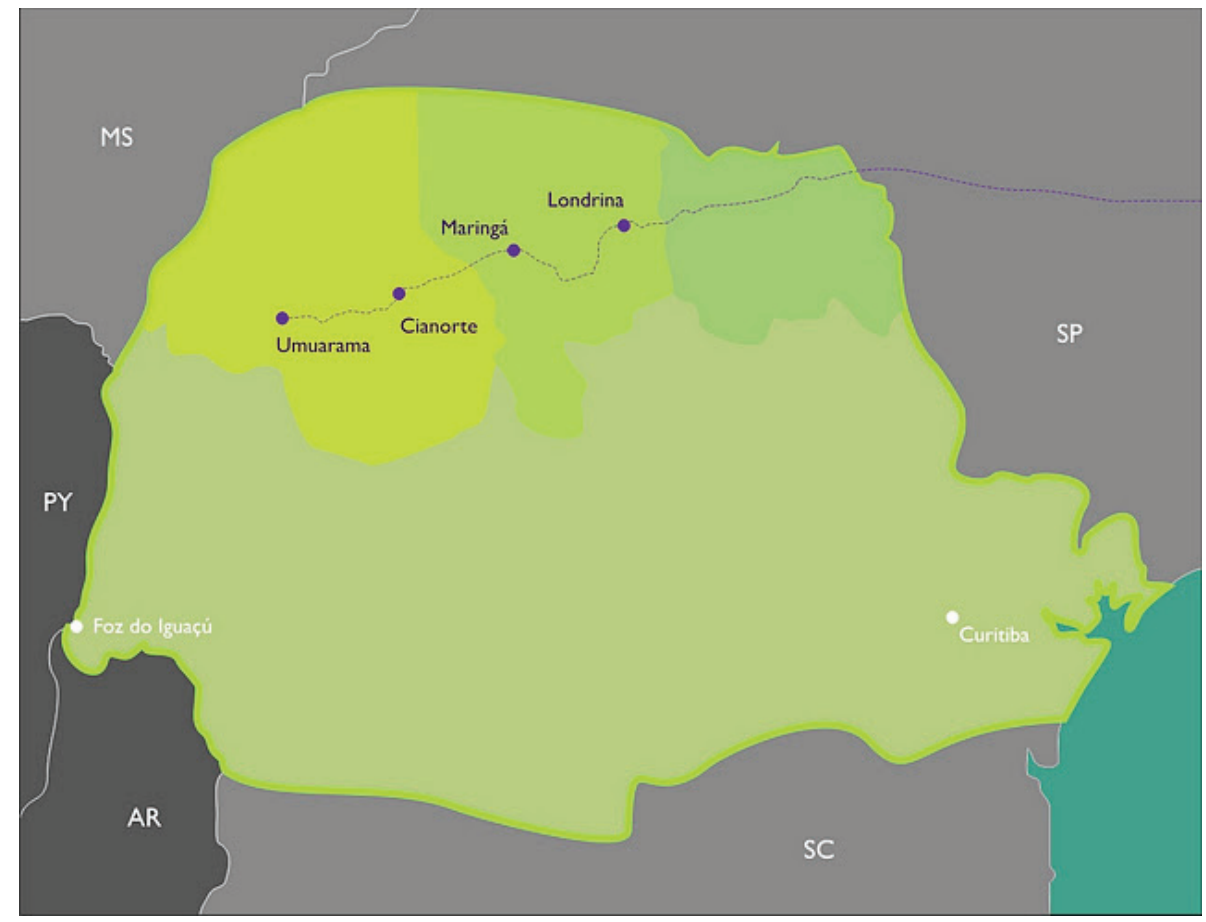

Figura 5: Mapa do Paraná10

Fonte: Gomes (2010).

Entre os anos de 1961 e 1962, o Paraná produziu 21,3 milhões de sacas de café. O centro produtor estava localizado na região Norte do Estado, principalmente pela qualidade do solo e clima propício para o desenvolvimento da lavoura cafeeira.

Em seu auge a cafeicultura paranaense atraiu pessoas de dentro e de fora do país, fosse para investir em terras no Estado ou à procura de trabalho e melhores condições de vida. O café trouxe povoamento, modernização e dinamizou os transportes e as comunicações. Em função do 'ouro negro', como o café foi chamado na época, muitas cidades enriqueceram. Em contrapartida, ao término de sua fase próspera, algumas cidades perderam importância ao passo que outras quase desapareceram.

10 Em destaque no mapa (da direita para a esquerda) estão as regiões do Norte Velho ou 'Pioneiro' (verde-escuro), Norte Novo (verde-médio) e Norte Novíssimo (verde-claro). 
A partirdos anos 1960, iniciaram-se as políticas governamentais para a racionalização do plantio da cafeicultura e pelo estímulo à diversificação do uso da terra, incentivando o plantio de novas culturas, como a soja, o milho e o trigo. Com a grande 'geada negra' de 1975, que abalou parte do Estado, houve um declínio de grandes proporções na produção cafeeira. Com os cafezais condenados pela geada, a maioria dos cafeicultores paranaenses optaram por utilizar os incentivos governamentais para diversificação da produção e substituíram o plantio de café por novas culturas agrícolas, como a soja e o milho. O cenário do campo paranaense começou a mudar. Mas o café não desapareceu definitivamente.

Atualmente o Brasil é o maior produtor mundial de café e responde por 30\% do mercado internacional do produto. É também o segundo mercado consumidor, ficando somente atrás dos Estados Unidos. O café continua sendo uma riqueza para o Brasil, geradora de empregos e movimentadora de grande quantia de dinheiro. As áreas produtoras de café estão concentradas no Centro-sul do país, destacando-se os Estados de Minas Gerais, São Paulo, Espírito Santo e Paraná. No entanto, a produção cafeeira está sofrendo uma queda no mundo todo. De acordo com a estimativa da Organização Internacional do Café (OIC), a safra mundial desse produto entre os anos de 2011 e 2012 deve apresentar redução de $4,33 \%$ em relação ao período anterior.

Atualmente, o Paraná possui 106 mil ha. dedicados ao cultivo do café. Para se estimular a produção cafeeira, houve a introdução do café adensado ${ }^{11}$ no Estado. Neste método, diminuem-se o espaço e o tamanho dos pés de café. O café adensado foi desenvolvido sob medida para as pequenas propriedades. O aumento da quantidade de pés de café por hectare impede a entrada de tratores e colheitadeiras nas áreas, favorecendo a contratação de mão de obra assalariada. Hoje o Paraná tem 13.000 produtores de café, dentre os quais, 64\% são da agricultura

11 Considera-se que uma lavoura é adensada quando o espaço livre entre as linhas de cafeeiros é igual a zero ou inferior a $20 \mathrm{~cm}$. A distância entre as covas na linha pode variar desde $1 \mathrm{~m}$ até $1,5 \mathrm{~m}$ para covas de duas plantas, ou de $0,5 \mathrm{~m}$ a $1 \mathrm{~m}$ para covas de uma planta, dependendo da variedade e local (ANDROCIOLI FILHO, 2005). 
familiar. A cafeicultura no Estado gera em torno de 70.000 empregos diretos e 210.000 empregos indiretos. Novas tecnologias e variedades estão sendo pesquisadas para dar mais espaçamento para o café adensado e, consequentemente, permitir maior produtividade para as pequenas propriedades agrícolas.

\section{Referências}

ANDROCIOLI FILHO, Armando. Ajuste de densidade e espaçamento. Cafeicultura, 18 dez. 2005. Disponível em: <http://www.revistacafeicultura.com.br/index.

php?tipo $=$ ler\&mat $=3648>$. Acesso em: 22 nov. 2011.

CANCIAN, Nadir Aparecida. Cafeicultura paranaense (1900-1970). Curitiba: Grafipar, 1981.

GOMES, Paulo Catto. História e formação. 2010. Disponível em: < http:// paulocattogomes.blogspot.com>. Acesso em: 23 nov. 2011.

POZZOBON, Irineu. A época do café no Paraná. Londrina: Grafmark, 2006.

PRADO JUNIOR, Caio. História econômica do Brasil. 26. ed. São Paulo: Brasiliense, 1981.

SIMONSEN, Roberto C. História econômica do Brasil (1500-1820). 7. ed. São Paulo: Ed.

Nacional; Brasília: INL/MEC, 1977.

WACHOWICZ, Ruy C. Norte Velho, Norte Pioneiro. Curitiba: Vicentina, 1987. 